\title{
三INTERF SPAC 8 \\ IMPACTOS DO PROGRAMA MINHA CASA MINHA VIDA EM \\ MARABÁ (PA): desigualdades socioespaciais nos conjuntos habitacionais Jardim do Éden e Tiradentes
}

\author{
IMPACTS OF THE PROGRAM MY HOUSE MY LIFE IN MARABÁ (PA): \\ socioespacial inequalities in the housing Jardim do Eden and Tiradentes
}

IMPACTOS DEL PROGRAMA MI CASA MI VIDA EN MARABÁ (PA): desigualdades socioespaciales en los conjuntos habitacionales Jardim do Éden y

Tiradentes

\begin{abstract}
Marcus Vinicius Mariano de Souza
Doutor em Geografia pela Universidade Federal de Uberlândia - UFU. Professor Adjunto da Universidade Federal do Sul e Sudeste do Pará - UNIFESSPA. marcussouza@unifesspa.edu.br

Myrelly Llays Rodrigues Leite

Graduanda em Geografia e Bolsista PIBIC/CNPq pela Universidade Federal do Sul e Sudeste do Pará - UNIFESSPA. myrellyr@gmail.com

Recebido para avaliação em 02/06/2017; Aceito para publicação em 07/11/2017.

\section{RESUMO}

O presente trabalho teve como objetivo analisar a produção do espaço urbano na cidade de Marabá (PA) a partir da lógica estatal, por meio da construção de conjuntos habitacionais do Programa Minha Casa Minha Vida, de forma que procurou-se verificar se esta produção tem possibilitado a inserção urbana das novas áreas ou levado ao estabelecimento de desigualdades socioespaciais. Tendo como referência espacial os conjuntos habitacionais Tiradentes e Jardim do Éden e a partir da aplicação de formulários nestes locais concluiu-se que a produção do espaço pela lógica estatal tem ampliado as desigualdades socioespaciais, na medida em que a decisão de se estabelecer neste local não pertence à sua população e não lhes foram dadas condições mínimas para reprodução social na cidade, manifestada na ausência dos equipamentos públicos de consumo coletivo.

Palavras-chave: Produção do Espaço Urbano; Desigualdades Socioespaciais; Inserção Urbana.

\section{ABSTRACT}

This study aimed to analyze the production of urban space in the city of Maraba (PA) from the state logic through the building housing the Minha Casa Minha Vida, so we tried to verify that this production has enabled the urban integration of the new areas and led to the establishment of socio-spatial inequalities. With the spatial reference the housing Tiradentes and the Jardim do Eden and from the application forms on these sites was found that the production of space by the state logic has expanded the socio-spatial inequalities, in that the decision to establish this site does not It belongs to its people and not have been given minimum conditions for social reproduction in the city, manifested in the absence of public facilities for collective consumption.
\end{abstract}

Keywords: Production of Urban Space; Socio-spatial Inequalities; Urban Integration.

\section{RESUMEN}


Dossiê: Impactos e repercussões territoriais de empreendimentos na Pan-Amazônia | Impactos do Programa Minha Casa Minha Vida em Marabá (PA): desigualdades socioespaciais nos conjuntos habitacionais Jardim do Éden e Tiradentes |

| Marcus Vinicius Mariano de Souza | Myrelly Llays Rodrigues Leite |

El presente trabajo tuvo como objetivo analizar la producción del espacio urbano en la ciudad de Marabá (PA) a partir de la lógica estatal, a través de la construcción de conjuntos habitacionales del Programa Mi Casa Mi Vida, de forma que se buscó verificar si esta producción tiene permitiendo la inserción urbana de las nuevas áreas o llevado al establecimiento de desigualdades socioespaciales. Con respecto a los conjuntos habitacionales Tiradentes y Jardim del Edén ya partir de la aplicación de formularios en estos lugares se concluyó que la producción del espacio por la lógica estatal ha ampliado las desigualdades socioespaciales en la medida en que la decisión de establecerse en este lugar no pertenece a su población y no se les han dado condiciones mínimas para la reproducción social en la ciudad, manifestada en ausencia de los equipos públicos de consumo colectivo.

Palabras-clave: Producción de Espacio Urbano; Desigualdades Socio-espaciales; Integración Urbana.

\section{INTRODUÇÃO}

Partindo do conceito de produção do espaço urbano, a análise realizada nesta pesquisa utiliza os aportes de Pedro Abramo (2010), de que existem diferentes lógicas de produção do espaço na sociedade capitalista brasileira, sendo estas a lógica de mercado, a lógica da necessidade e a lógica estatal. Esta última lógica, atualmente, tem se apresentado na paisagem das cidades, enquanto forma urbana, através da construção de conjuntos habitacionais, sobretudo após a criação do Programa Minha Casa Minha Vida (PMCMV), a partir de 2009.

Autoras como Shimbo (2010) e Fix (2011) concordam que a política habitacional 'atual' (final da primeira década do século XXI) se apresenta em duas faces distintas: em uma delas, o poder público financia e produz diretamente a habitação, como no caso dos programas habitacionais tradicionais; do outro lado, o mesmo poder público procede a um conjunto de medidas, como a flexibilização e ampliação de crédito, para favorecer a produção pelo setor privado, estimulando o mercado imobiliário.

Entre os efeitos que o PMCMV teve no mercado imobiliário está a garantia de credibilidade aos papeis das empresas que tinham aberto capital na Bolsa de Valores, a consolidação e ampliação da demanda por terra (CARDOSO; ARAGÃO, 2011), aliada à elevação do preço desta, além da ampliação do público consumidor para classes que estavam antes fora do mercado e a criação de um mercado imobiliário nacional (MELAZZO, 2013).

Dentro desse pacote de novas estratégias e de expansão do mercado imobiliário para outras áreas do país, um dos movimentos realizados pelos empreendedores imobiliários, sobretudo nas cidades médias e de porte médio que agora se incorporavam a este circuito, é a incorporação de terrenos, muitas vezes através de aliança entre incorporadores externos e proprietários fundiários locais, levando à formação de um 
Dossiê: Impactos e repercussões territoriais de empreendimentos na Pan-Amazônia | Impactos do Programa Minha Casa Minha Vida em Marabá (PA): desigualdades socioespaciais nos conjuntos habitacionais Jardim do Éden e Tiradentes |

| Marcus Vinicius Mariano de Souza | Myrelly Llays Rodrigues Leite |

verdadeiro banco de terrenos, cuja transformação em moradia efetiva nem sempre está garantida, ampliando a efetivação da cidade-mercadoria em detrimento das reais necessidades de moradia da população, contexto no qual se insere Marabá.

Entretanto, a efetivação do PMCMV em Marabá, através da criação de conjuntos habitacionais, tem levado ao surgimento de outras dinâmicas: os problemas relativos à inserção urbana dos conjuntos habitacionais analisados e, por conseguinte, a ampliação de desigualdades socioespaciais.

A chegada de investimentos habitacionais em cidades médias como Marabá, por meio da criação de conjuntos habitacionais, poderia dar uma importante contribuição para a diminuição do déficit habitacional urbano. Entretanto, este não tem sido o resultado mais expressivo do PMCMV, de forma que o que se percebe a partir da instalação destes conjuntos é a exacerbação de outros problemas, que contribuem para a ampliação das desigualdades socioespaciais. Entre tais problemas está a falta de equipamentos públicos de saúde e educação nestes conjuntos, reforçando o problema da inserção urbana, entendido aqui a partir de Ferreira (2012), cujos parâmetros para análise são a presença e otimização da infraestrutura e serviços urbanos; a localização e acessibilidade e a fluidez urbana.

Nesse sentido, o objetivo do presente trabalho foi analisar a produção do espaço urbano de Marabá, a partir da instalação de conjuntos habitacionais da Faixa 1 do Programa Minha Casa Minha Vida, de modo a verificar se este viés de produção espacial está garantindo a inserção urbana das novas áreas e sua população ou, de modo contrário, tem provocado a ampliação de desigualdades socioespaciais na referida cidade. Para tal, a análise teve como recorte espacial os conjuntos habitacionais Residencial Tiradentes e Residencial Jardim do Éden, lançados em Marabá em 2013 e 2015, respectivamente.

Metodologicamente, o desenvolvimento do trabalho realizou, além da pesquisa bibliográfica e do levantamento de dados primários e secundários, a aplicação de formulários nos conjuntos, com objetivo traçar um perfil das populações destes locais e compreender como se dá o acesso à cidade e aos equipamentos coletivos públicos, a fim de verificar se a produção do espaço urbano recente tem levado à ampliação das desigualdades socioespaciais ou se a inserção urbana está sendo plenamente realizada.

De tal forma, utilizando-se da técnica de amostragem aleatória simples, com nível de confiança de 95\%, foram aplicados 331 formulários, para um universo de 2.378 residências. A partir da aplicação dos formulários e sua posterior análise foi possível perceber as estratégias da população residente neste local, no que diz respeito ao acesso desta à cidade e aos equipamentos e serviços básicos de consumo coletivo, demonstrando 
Dossiê: Impactos e repercussões territoriais de empreendimentos na Pan-Amazônia | Impactos do Programa Minha Casa Minha Vida em Marabá (PA): desigualdades socioespaciais nos conjuntos habitacionais Jardim do Éden e Tiradentes |

| Marcus Vinicius Mariano de Souza | Myrelly Llays Rodrigues Leite |

que a produção do espaço urbano a partir da lógica estatal tem colaborado para dificultar a inserção urbana destas áreas e seus moradores e, por conseguinte, permitindo a ampliação das desigualdades socioespaciais, como será descrito no decorrer deste trabalho.

\section{O PMCMV E A PRODUÇÃO DO ESPAÇO URBANO}

Nos últimos anos, sobretudo após a crise financeira internacional de 2008, houve uma significativa mudança nos padrões de atuação do mercado imobiliário e da construção civil no Brasil, sobretudo a partir do momento em que o Estado Brasileiro dispôs de medidas para diminuir os efeitos da referida crise no país, como aconteceu através do Programa Minha Casa Minha Vida (PMCMV). Por meio do programa, lançado como medida anticrise, expandiu-se a produção imobiliária, através da ampliação do crédito para aquisição e construção de moradias (MELAZZO, 2013).

Nesse contexto, cidades médias como Marabá (PA) tornaram-se bastante atrativas ao capital imobiliário, já que produtos imobiliários comuns nas regiões metropolitanas, como condomínios fechados, se apresentariam como o "novo habitat urbano" para as populações destas cidades. Mas também a produção de moradias em conjuntos habitacionais, por meio de empresas privadas, em aliança com os poderes públicos municipais, tornou-se uma importante marca deste programa.

Segundo Fix (2011), durante a crise internacional de 2008 percebeu-se que as ações na bolsa de valores ligadas aos empreendimentos imobiliários apresentavam um forte viés especulativo, fazendo com que muitas empresas não pudessem cumprir as metas prometidas. Pelo fato da construção civil ser um setor que gera expressiva quantidade de empregos, isso é usado pelo governo para apresentar um pacote de medidas para superar a crise, que tem como carro-chefe o PMCMV, lançado em abril de 2009 (FIX, 2011).

Fix (2011) demonstra que a articulação entre o empreendedor imobiliário e os segmentos políticos locais é capaz de levar à alteração da legislação local (como as leis que definem o perímetro urbano, por exemplo), a fim de se disponibilizar terra até então rural em um mercado imobiliário urbano, favorecendo não apenas as empresas incorporadoras e os associados a elas, mas também os proprietários fundiários locais (por vezes, inseridos na classe política). As terras pertencentes a estes, nem sempre, são aquelas mais adequadas à promoção imobiliária, mostrando outra faceta destas estratégias, que é a incorporação de áreas precárias em infraestruturas e condições de acesso, como já afirmava também Botelho (2007). 
Dossiê: Impactos e repercussões territoriais de empreendimentos na Pan-Amazônia | Impactos do Programa Minha Casa Minha Vida em Marabá (PA): desigualdades socioespaciais nos conjuntos habitacionais Jardim do Éden e Tiradentes |

\section{| Marcus Vinicius Mariano de Souza | Myrelly Llays Rodrigues Leite |}

Este processo de promover a incorporação urbana de áreas já precárias em infraestruturas e acessos acarreta em outro problema, que é onerar os cofres públicos pela necessidade de se levar até estas novas áreas os equipamentos básicos à reprodução social, como as redes de infraestruturas, transporte público, equipamentos de saúde, educação e lazer, entre outros. Nesse sentido, o PMCMV 'colaborou' para a apropriação de renda pelos proprietários de terra e no aumento das desigualdades para os moradores do programa.

\footnotetext{
O espraiamento resultante desse modelo tem alto custo para o poder público, uma vez que a rede de infraestrutura (sistema viário, água, saneamento, energia, etc.), transportes e serviços (escola, cultura, lazer, etc.) terá que ser estendida. O pacote foi inicialmente lançado sem estímulo à ocupação de imóveis construídos vagos, apesar dos inúmeros edifícios vazios existentes nos centros urbanos e das políticas urbanas já elaboradas para favorecer seu uso. Prevalece, assim, a lógica de produção que interessa ao setor da construção (FIX, 2011, p. 143).
}

Em Marabá, entre os anos de 2012 e 2015, foram construídos e entregues à população três conjuntos habitacionais, através dos incentivos governamentais do PMCMV, naquilo que o programa classifica como Faixa 1 (imóveis para famílias com renda entre zero e três salários mínimos). No referido período surgiram os residenciais Vale do Tocantins (em 2012, com 1.090 habitações), Tiradentes (em 2013, com 1.410 habitações) e Jardim do Éden (em 2015, com 968 habitações), totalizando 3.468 novas residências. Encontra-se, ainda, em construção, o Residencial Magalhães, com disponibilizará à população 2.500 novas residências. Todos estes conjuntos estão localizados na margem direita do Rio Tocantins, nos Núcleos Urbanos de São Félix e Morada Nova (FIGURA 1)

Assim, a construção das moradias poderia resolver, parcialmente, o problema do déficit habitacional marabaense. Entretanto, o que se percebe a partir da instalação destes conjuntos é a exacerbação de outros problemas, que contribuem para a ampliação das desigualdades socioespaciais em Marabá. Entre tais problemas está a falta de equipamentos públicos de saúde e educação nestes conjuntos, o que aumenta a demanda pelos equipamentos do entorno (São Félix e Morada Nova), problemas com abastecimento de água, entre outros. 
Dossiê: Impactos e repercussões territoriais de empreendimentos na Pan-Amazônia | Impactos do Programa Minha Casa Minha Vida em Marabá (PA): desigualdades socioespaciais nos conjuntos habitacionais Jardim do Éden e Tiradentes |

| Marcus Vinicius Mariano de Souza | Myrelly Llays Rodrigues Leite |

Marabá - Localização dos residenciais do PMCMV, Faixa 1 (2016)

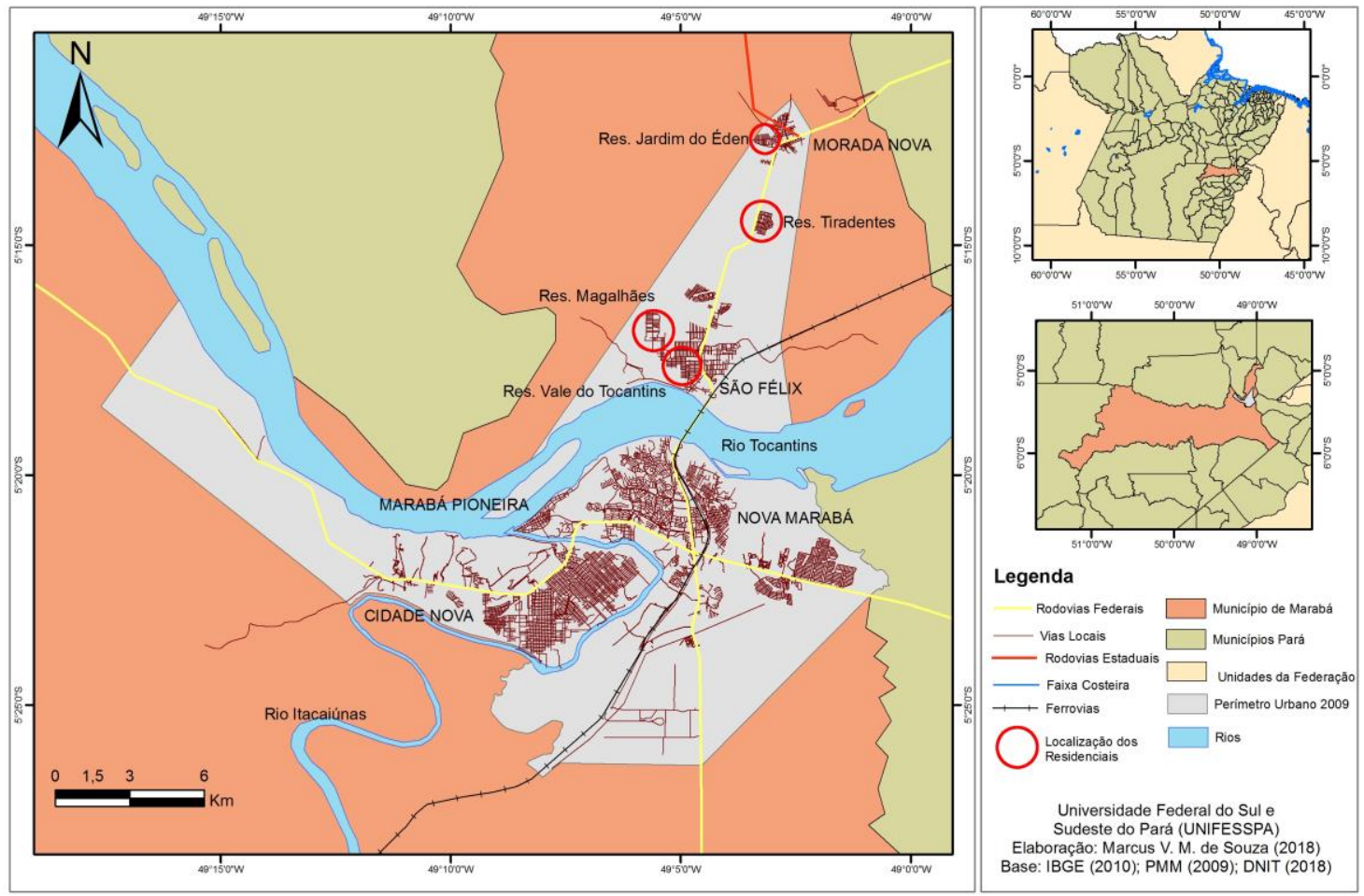

Figura 1 - Marabá: Localização dos residenciais do PMCMV, Faixa 1 (2016)

Elaboração: Souza (2016).

A situação atual destes conjuntos habitacionais reforça o problema da inserção urbana (FERREIRA, 2012), pois apesar de estarem próximos à BR-155, que lhes dá acesso, a articulação destes espaços com o restante da cidade, por meio dos deslocamentos de seus habitantes, é dificultada à medida que o transporte público coletivo não consegue atender a demanda criada com a instalação destes conjuntos.

Percebe-se que o PMCMV contribuiu para a ampliação das desigualdades socioespaciais em algumas cidades, como se pretende demonstrar a seguir, pois ele não atacou diretamente o problema do déficit habitacional, já que possibilitou a incorporação de terras e consequente expansão territorial da cidade através da disponibilização de créditos para a criação de loteamentos, por exemplo, e não pela criação da moradia efetiva.

JARDIM DO ÉDEN E TIRADENTES: as desigualdades socioespaciais a partir do PMCMV

A pesquisa realizada nos conjuntos habitacionais do PMCMV (Residencial Tiradentes e Jardim do Éden) teve como procedimento metodológico a pesquisa de campo e a aplicação de formulários. Assim, a aplicação dos formulários possibilitou os 
Dossiê: Impactos e repercussões territoriais de empreendimentos na Pan-Amazônia | Impactos do Programa Minha Casa Minha Vida em Marabá (PA): desigualdades socioespaciais nos conjuntos habitacionais Jardim do Éden e Tiradentes |

| Marcus Vinicius Mariano de Souza | Myrelly Llays Rodrigues Leite |

levantamentos de dados em sete conjuntos de variáveis, a saber: Caracterização Socioeconômica da Família; Acesso ao Trabalho; Utilização dos Serviços de Saúde; Utilização dos Serviços/Equipamentos de Educação; Utilização dos Serviços/ Equipamentos de Lazer; Relações de Comércio e Consumo; Percepção sobre o local de Moradia. Nesse sentido, os resultados estão apresentados a seguir:

Com relação às características socioeconômicas destaca-se o local de origem das famílias, o que é fundamental para compreender a dinâmica da produção do espaço urbano. Primeiro deve-se levar em consideração que ambos conjuntos estão localizados na margem direita do rio Tocantins, nas imediações dos núcleos urbanos de São Félix e Morada Nova. No caso do Residencial Tiradentes, $45 \%$ da população é oriunda destes núcleos urbanos de Marabá, sendo, portanto, a maioria originária de outras áreas da cidade e até mesmo de outros municípios. No caso do Jardim do Éden, $51 \%$ da população têm como área de origem os núcleos de São Félix e Morada Nova. Nesse sentido, percebe-se que o Residencial Tiradentes provocou um maior deslocamento de pessoas do que o Jardim do Éden, mas, em ambos os casos, há de se considerar que uma parcela significativa de pessoas ( $55 \%$ e $49 \%$, respectivamente), não era moradora dos arredores destes conjuntos, o que causa um aumento na pressão sobre os equipamentos públicos existentes, como escolas e postos de saúde e um aumento na demanda por transportes para esta área.

Outra informação obtida com a aplicação dos formulários foi com relação à renda das famílias. Assim, foi possível verificar que a maioria das famílias (57\%) do Residencial Tiradentes possui renda compreendida entre zero e um salário mínimo. Isto é explicado, em parte, pelo baixo número de pessoas por residência que trabalham. Em 54,8\% das residências apenas um morador possui emprego e em outros 19,3\% das residências nenhum morador trabalhava naquele momento. Além disso, entre os chefes de família, verificou-se que 30,1\% estavam desempregados no momento de aplicação dos formulários. 
Dossiê: Impactos e repercussões territoriais de empreendimentos na Pan-Amazônia | Impactos do Programa Minha Casa Minha Vida em Marabá (PA): desigualdades socioespaciais nos conjuntos habitacionais Jardim do Éden e Tiradentes |

| Marcus Vinicius Mariano de Souza | Myrelly Llays Rodrigues Leite |

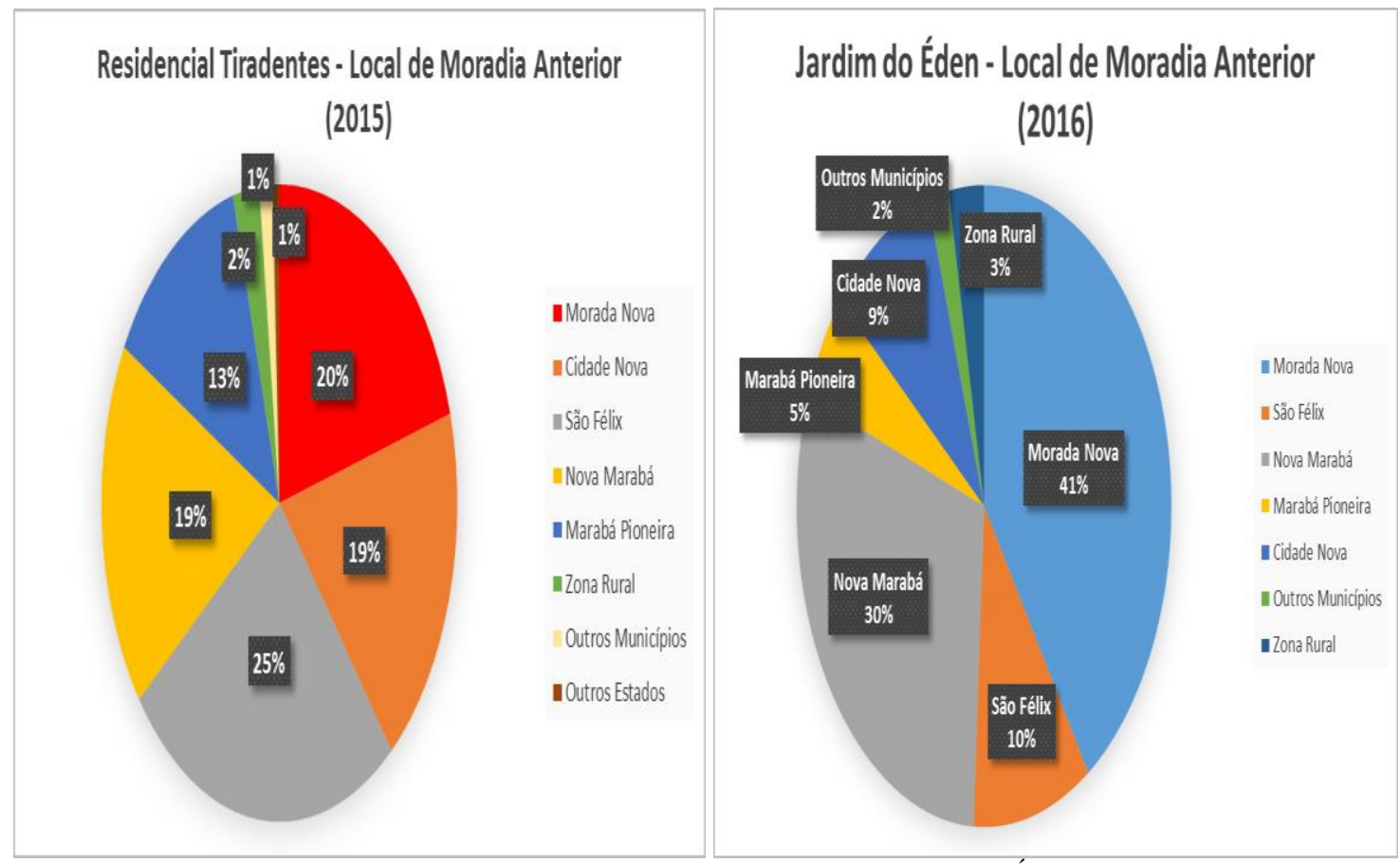

Figura 2 - Local de Moradia Anterior da população do Tiradentes e Jardim do Éden (2015-2016) Organização: Souza; Leite (2016). Fonte: Pesquisa de Campo (2015-2016).

No caso do Jardim do Éden, 68\% das famílias possuem renda entre zero e um salário mínimo, já que em 61\% das residências apenas um morador possui emprego. Em $22 \%$ das residências não havia ninguém trabalhando no momento da pesquisa (janeiro de 2016). Além disso, naquele momento, em 38,3\% das residências do Jardim do Éden, o chefe de família encontrava-se desempregado. Assim, percebe-se que em ambos residenciais se apresenta uma situação de vulnerabilidade socioeconômica e que esta situação é mais grave no Jardim do Éden.

Com relação à inserção urbana, um fator fundamental é a acessibilidade dos moradores dos bairros aos equipamentos e serviços públicos de consumo coletivo. Nesse sentido, os conjuntos habitacionais apresentam graves problemas devido à ausência de tais equipamentos. Atualmente, o único equipamento público existente é uma Creche no Residencial Tiradentes. Escolas e postos de saúde são inexistentes, o que torna necessário o deslocamento a outros bairros. Esta situação se agrava com a precariedade na prestação do serviço público de transporte, segundo alegação dos moradores. Nos mapas a seguir estão apresentadas as localizações das escolas e postos de saúde nas imediações dos conjuntos habitacionais.

A figura a seguir apresenta a localização e a área de abrangência das escolas de Ensino Fundamental dos núcleos São Félix e Morada Nova. A partir da localização destas escolas, realizada através de trabalho de campo e marcação das coordenadas da escola com 
Dossiê: Impactos e repercussões territoriais de empreendimentos na Pan-Amazônia | Impactos do Programa Minha Casa Minha Vida em Marabá (PA): desigualdades socioespaciais nos conjuntos habitacionais Jardim do Éden e Tiradentes |

| Marcus Vinicius Mariano de Souza | Myrelly Llays Rodrigues Leite |

GPS, foram determinados quatro raios concêntricos, as seguintes escalas de distância: 500 metros, 1000 metros, 1500 metros e 2000 metros.

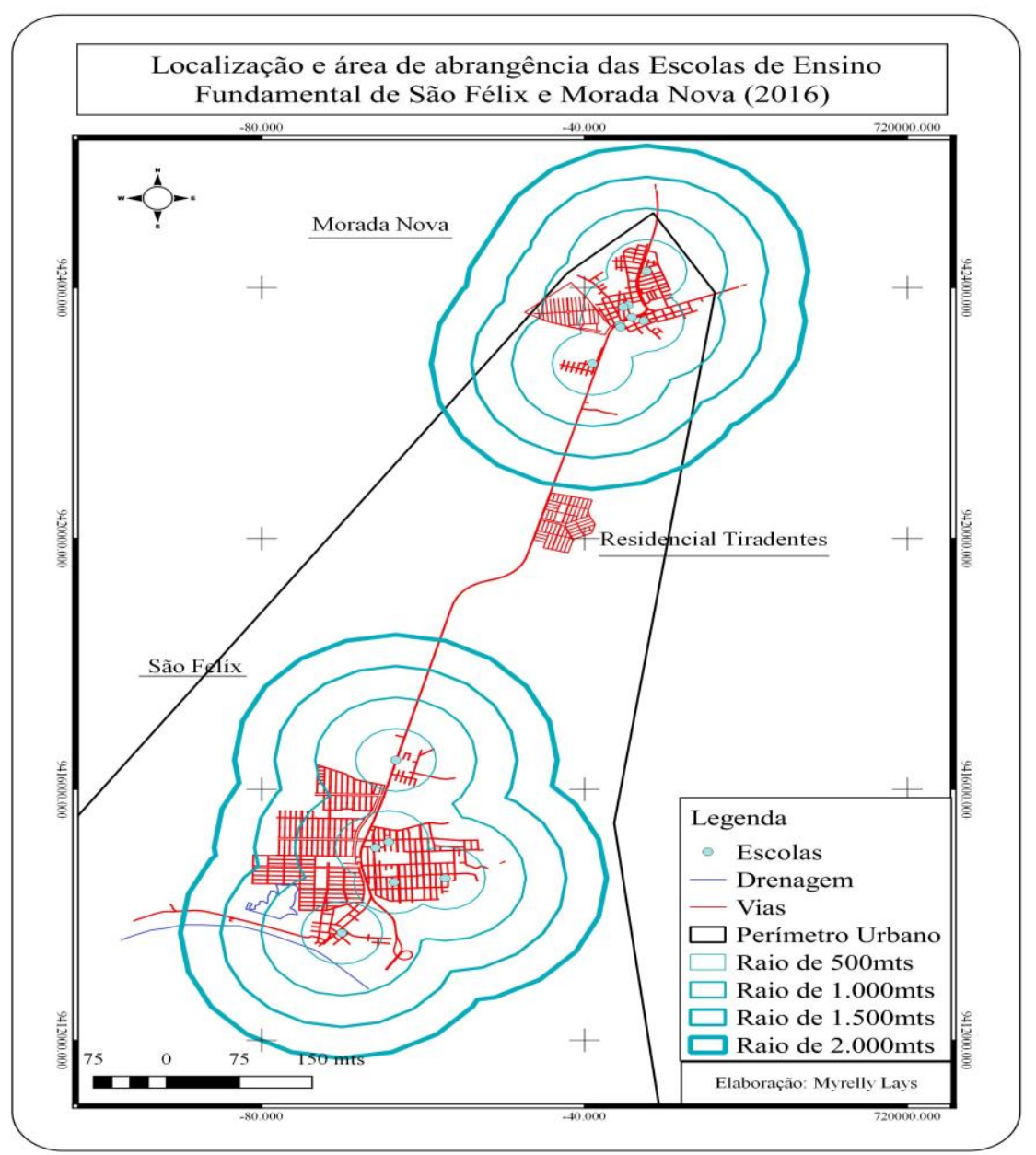

Figura 3 - Localização e área de abrangência das Escolas de Ensino Fundamental de São Félix e Morada Nova (2016)

Elaboração: Leite (2016) / Fonte: Pesquisa de Campo (2016).

Através da pesquisa de campo foram identificadas sete escolas de Ensino Fundamental no Núcleo São Félix e seis no núcleo Morada Nova. Vale ressaltar que nenhuma destas escolas está localizada nos conjuntos habitacionais em análise. A partir da análise da Figura 3 anterior pode-se perceber a situação de dificuldade à qual se submete a população do Residencial Tiradentes para conseguir acesso à educação básica. Considerando a localização do residencial, não existe nenhuma escola no seu entorno que esteja em um raio mínimo de 2000 metros de distância.

Isso se agrava na medida em que $73 \%$ das residências do Tiradentes possuem crianças e/ou jovens em idade escolar. Para minimizar tal situação, o poder público municipal tem colocado ônibus escolares para transportar as crianças do Tiradentes até a escola. Este é o principal meio de deslocamento das crianças e jovens à escola, perfazendo 
Dossiê: Impactos e repercussões territoriais de empreendimentos na Pan-Amazônia | Impactos do Programa Minha Casa Minha Vida em Marabá (PA): desigualdades socioespaciais nos conjuntos habitacionais Jardim do Éden e Tiradentes |

| Marcus Vinicius Mariano de Souza | Myrelly Llays Rodrigues Leite |

um total de $84 \%$. O principal destino dos jovens escolares para acesso à educação são as escolas do núcleo Morada Nova, num total de 75\%. Entretanto, mesmo com a existência do ônibus escolar, para minimizar a distância das escolas em relação ao residencial, foi possível perceber que em pelo menos $6 \%$ das residências as crianças e jovens não frequentam escolas, o que já indica a evasão escolar.

No caso do Jardim do Éden, também é possível perceber que a construção deste conjunto habitacional aumentou a pressão sobre a demanda por vagas nas escolas, sobretudo do Núcleo Morada Nova (lembrando aqui que 49\% da população é originária de outras áreas da cidade). Em 71\% das residências existem crianças e jovens em idade escolar. O Jardim do Éden está inserido num raio de 1000 metros de distância para todas as escolas do núcleo Morada Nova, sendo que este é o principal destino dos jovens escolares (94\%), o que explica o fato de $87 \%$ das crianças/jovens acessarem a escola a pé, não necessitando do transporte escolar, como no caso do Residencial Tiradentes. Entretanto, mesmo diante de uma situação mais favorável do que no caso do Tiradentes, ainda assim foi encontrada uma taxa de 7\% de residências com crianças e jovens fora da escola. A situação do acesso ao Ensino Médio é o principal problema no que diz respeito ao acesso à educação para os dois conjuntos analisados, como pode ser visto a partir da Figura 4.

Em toda área de São Félix e Morada Nova existem apenas duas escolas de Ensino Médio: a Escola Estadual Walquise Viana, em São Félix II e a Escola Estadual Gabriel Pimenta, em Morada Nova. Assim como no caso das escolas de Ensino Fundamental, o residencial Tiradentes está a mais de 2000 metros de distância de qualquer uma destas escolas. O transporte escolar funciona como alternativa de acesso a estes equipamentos públicos. Entretanto, durante a realização das pesquisas, os moradores relataram que, diante da ocorrência de greves na rede municipal de ensino, o transporte público deixou de ser realizado, o que prejudicou os alunos do ensino médio, já que este é de responsabilidade do Governo Estadual e, portanto, não existe transporte escolar específico para estes. 
Dossiê: Impactos e repercussões territoriais de empreendimentos na Pan-Amazônia | Impactos do Programa Minha Casa Minha Vida em Marabá (PA): desigualdades socioespaciais nos conjuntos habitacionais Jardim do Éden e Tiradentes |

| Marcus Vinicius Mariano de Souza | Myrelly Llays Rodrigues Leite |

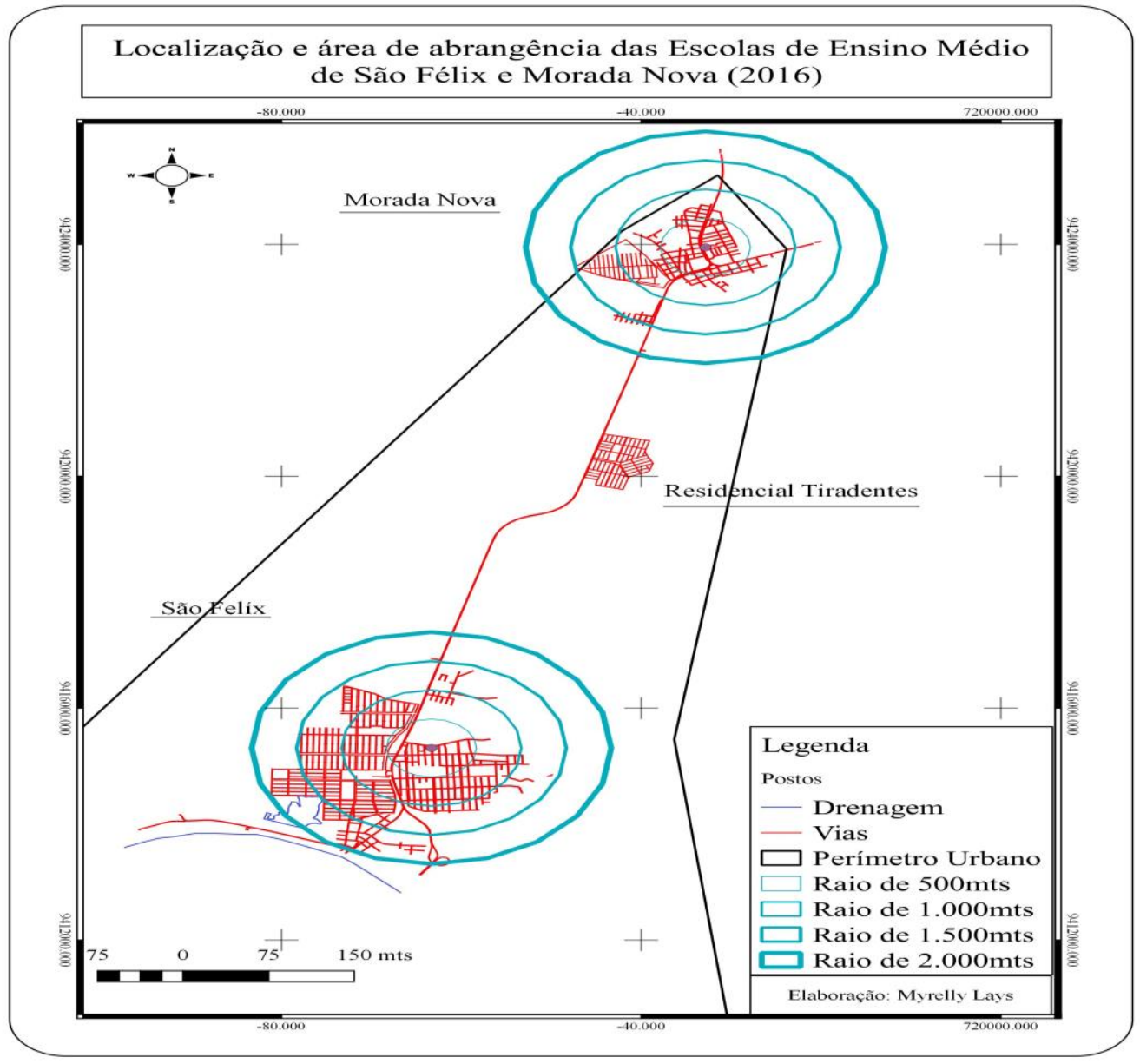

Figura 4- Localização e área de abrangência das Escolas de Ensino Médio de São Félix e Morada Nova (2016)

Elaboração: Leite (2016) / Fonte: Pesquisa de Campo (2016).

No caso do Jardim do Éden, a distância do bairro em relação à escola aumentou, em comparação com o ensino fundamental. Nesse caso, uma parte do residencial está no raio de 1500 metros de distância da escola. Inferimos que o aumento da demanda sobre as vagas de ensino médio e a existência de apenas duas escolas nesta área da cidade, aliado ao fator transporte, pode ser parte da explicação para a evasão escolar dos alunos dos conjuntos em habitacionais em questão.

No que diz respeito ao acesso aos equipamentos/serviços públicos de saúde a situação é bastante parecida com o caso da educação. A criação destes dois conjuntos habitacionais fez com que aumentasse a demanda pela prestação dos serviços de saúde nos Postos de atendimento dos núcleos São Félix e Morada Nova. Existem atualmente dois postos no núcleo São Félix e apenas um Morada Nova, sendo que este é o mais demandado tanto pela população do Residencial Tiradentes quanto do Jardim do Éden, conforme consta na figura a seguir. 
Dossiê: Impactos e repercussões territoriais de empreendimentos na Pan-Amazônia | Impactos do Programa Minha Casa Minha Vida em Marabá (PA): desigualdades socioespaciais nos conjuntos habitacionais Jardim do Éden e Tiradentes |

| Marcus Vinicius Mariano de Souza | Myrelly Llays Rodrigues Leite |

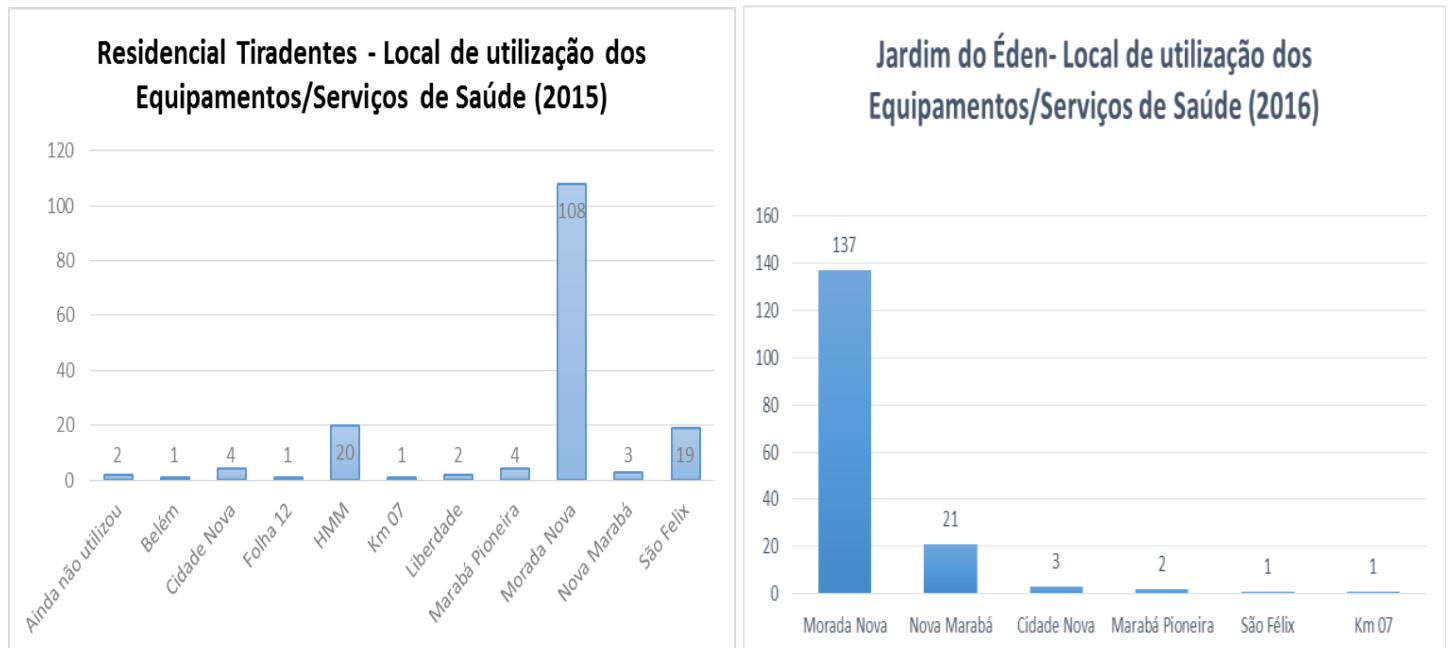

Figura 5 - Residencial Tiradentes e Jardim do Éden: local de utilização dos equipamentos/serviços de saúde (2015 e 2016)

Organização: Souza; Leite (2016). Fonte: Pesquisa de Campo (2015-2016).

Na Figura 6 está a localização dos postos de saúde de São Félix e Morada Nova e os raios de abrangência, assim como no caso das escolas. Mais uma vez, a situação do Residencial Tiradentes, em relação à sua localização, demonstra a dificuldade de acesso aos equipamentos públicos coletivos. Nenhum dos três postos de saúde está a uma distância menor do que 2000 metros deste residencial, o que faz com que $85 \%$ da população tenham que recorrer ao transporte público para acessar este serviço.

Já em relação ao Jardim do Éden, este fica localizado no raio de abrangência de 1500 metros de distância do posto de saúde do núcleo Morada Nova. Isso explica o deslocamento da população para acessar este serviço ser realizado, em sua maioria (65\%), a pé.

A necessidade de deslocar-se para a utilização de equipamentos públicos de consumo coletivo torna imprescindível a existência de um serviço público de transportes de boa qualidade. Entretanto, durante a pesquisa de campo foi possível perceber que existem apenas duas linhas de ônibus que conectam os conjuntos habitacionais ao restante da cidade: a linha Marabá Pioneira-Morada Nova e a linha Morada Nova-Novo Horizonte, sendo que a linha que liga ao Novo Horizonte (Núcleo Cidade Nova) possui apenas um horário de saída dos bairros (05h40 da manhã) e um de retorno (19h). Assim, durante o horário comercial, o morador que necessitar se deslocar até o núcleo Cidade Nova precisará pagar por duas passagens (uma até a Marabá Pioneira e outra deste núcleo até a Cidade Nova). 
Dossiê: Impactos e repercussões territoriais de empreendimentos na Pan-Amazônia | Impactos do Programa Minha Casa Minha Vida em Marabá (PA): desigualdades socioespaciais nos conjuntos habitacionais Jardim do Éden e Tiradentes |

| Marcus Vinicius Mariano de Souza | Myrelly Llays Rodrigues Leite |

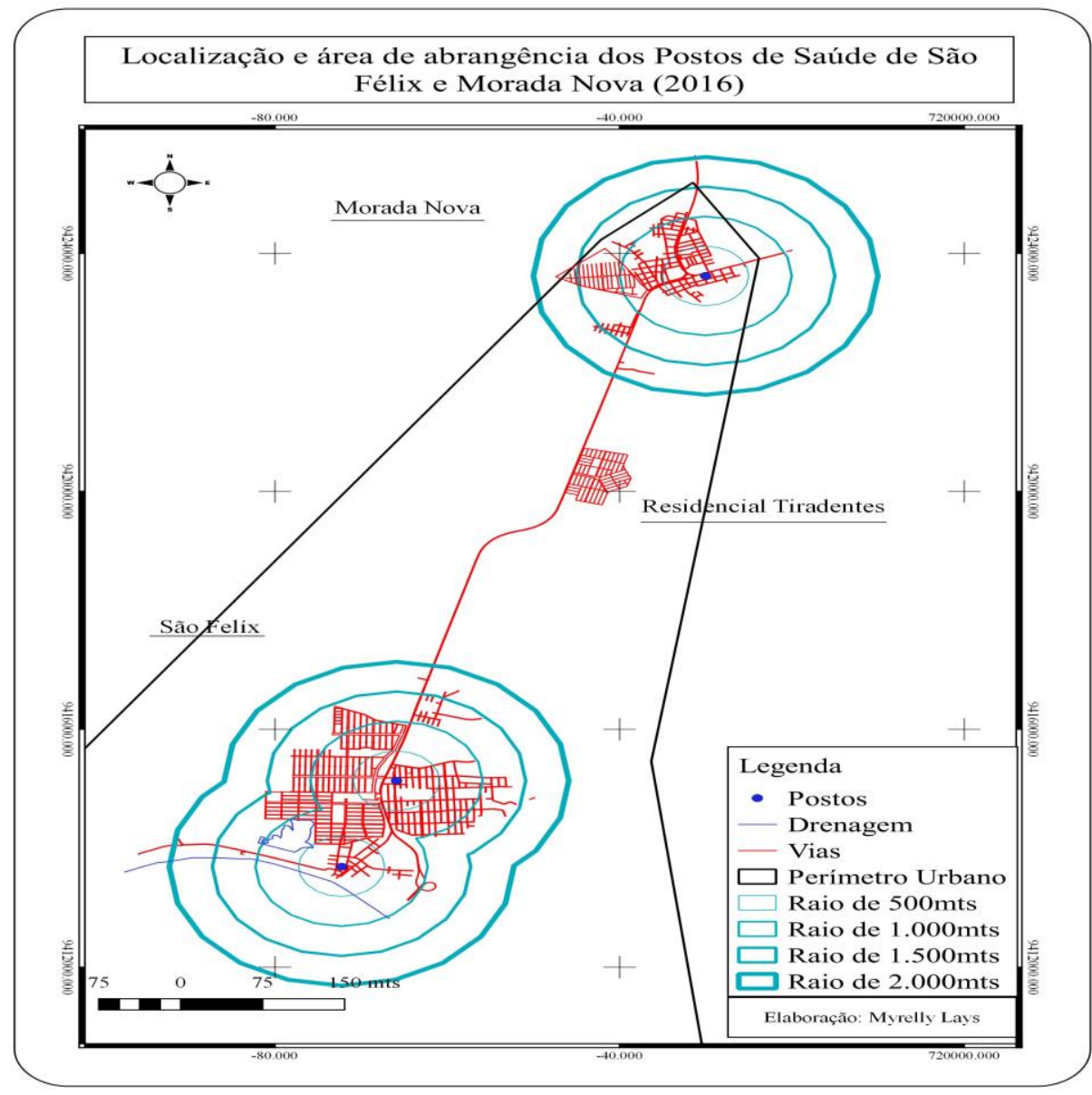

Figura 6 - Localização e área de abrangência dos Postos de Saúde de São Félix e Morada Nova (2016) Elaboração: Leite (2016) / Fonte: Pesquisa de Campo (2016).

Nesse sentido, a partir da Figura 7 é possível ver o trajeto da principal linha de transporte coletivo que conecta os conjuntos ao restante da cidade, que é a linha Marabá Pioneira-Morada Nova. A partir da rota da linha, foram marcados com GPS os pontos de parada do ônibus e, a partir destes, dois raios (de 500 e 1000 metros), para demonstrar tanto a macroacessibilidade quanto a microacessibilidade, conforme os conceitos de Vasconcelos (2001). A macroacessibilidade diz respeito à variedade de destinos que podem ser alcançados e, consequentemente, a teia de relações sociais, econômicas, políticas e culturais do habitante. Já a microacessibilidade diz respeito à facilidade de ter acesso direto aos destinos desejados, como por exemplo, as condições de acesso entre o ponto de parada e o destino final do passageiro (VASCONCELOS, 2001).

A partir da Figura 7 podemos inferir que a macroacessibilidade dos moradores do Residencial Tiradentes é limitada a alguns espaços da cidade, sobretudo partes do núcleo Nova Marabá e da Marabá Pioneira. Poderíamos classificar isso como macroacessibilidade direta, pois considerando a principal forma de ligação do residencial com o restante da 
Dossiê: Impactos e repercussões territoriais de empreendimentos na Pan-Amazônia | Impactos do Programa Minha Casa Minha Vida em Marabá (PA): desigualdades socioespaciais nos conjuntos habitacionais Jardim do Éden e Tiradentes |

| Marcus Vinicius Mariano de Souza | Myrelly Llays Rodrigues Leite |

cidade, via transporte público, que é a linha Marabá Pioneira - Morada Nova, o morador terá acesso somente aos núcleos urbanos da Nova Marabá e Marabá Pioneira.

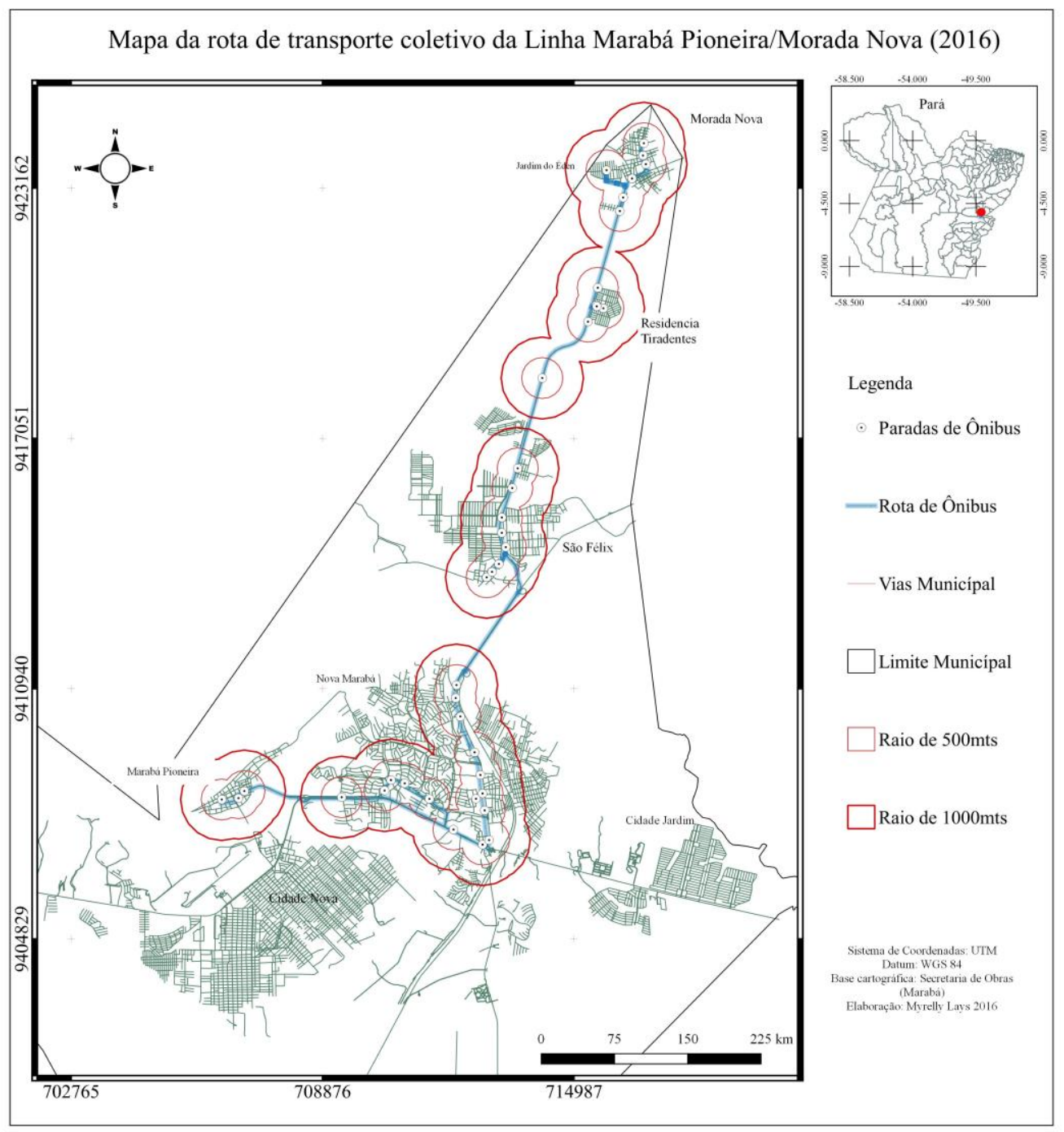

Figura 7 - Mapa da linha de transporte coletivo que atende o Residencial Tiradentes - Marabá (PA), 2016 Elaboração: Souza; Leite (2016) / Fonte: Pesquisa de Campo (2016).

Nesse sentido, pode-se também pensar em uma macroacessibilidade indireta, considerando que o morador destes núcleos pode acessar outras áreas da cidade a partir do momento em que este se desloca para a Marabá Pioneira e lá pode utilizar outras linhas do transporte coletivo. Entretanto, como em Marabá o sistema de transporte público não é integrado, ao realizar esta troca de linhas o usuário é obrigado a pagar outra passagem, o que no caso dos moradores do Residencial Tiradentes é um agravante, haja vista as condições socioeconômicas dos moradores desta localidade, cuja renda familiar é, em sua maioria, entre zero e um salário mínimo, como já demonstrado anteriormente.

Sobre a microacessibilidade, a partir do raio de abrangência dos pontos de parada do transporte coletivo, pode-se inferir que essa também fica comprometida para os 
Dossiê: Impactos e repercussões territoriais de empreendimentos na Pan-Amazônia | Impactos do Programa Minha Casa Minha Vida em Marabá (PA): desigualdades socioespaciais nos conjuntos habitacionais Jardim do Éden e Tiradentes |

| Marcus Vinicius Mariano de Souza | Myrelly Llays Rodrigues Leite |

moradores dos conjuntos habitacionais em análise. Considerando o raio de 500 metros, pode-se verificar que uma parcela significativa de áreas da cidade, sobretudo do núcleo Nova Marabá, está fora desse raio, o que significa que, para acessar tais áreas, o morador dos conjuntos terá que se deslocar mais de 500 metros, provavelmente a pé, para acessar destinos finais, como por exemplo, local de trabalho. Esta distância (500 metros) é considerada por Ferraz e Torres (2001) como o limite máximo para uma acessibilidade regular entre o ponto de parada e o destino final, para áreas urbanas. Neste caso, vale ressaltar que a Nova Marabá é um importante local de trabalho dos chefes de família dos conjuntos analisados, em especial no caso do Residencial Tiradentes, conforme aparece na Figura 8 adiante.

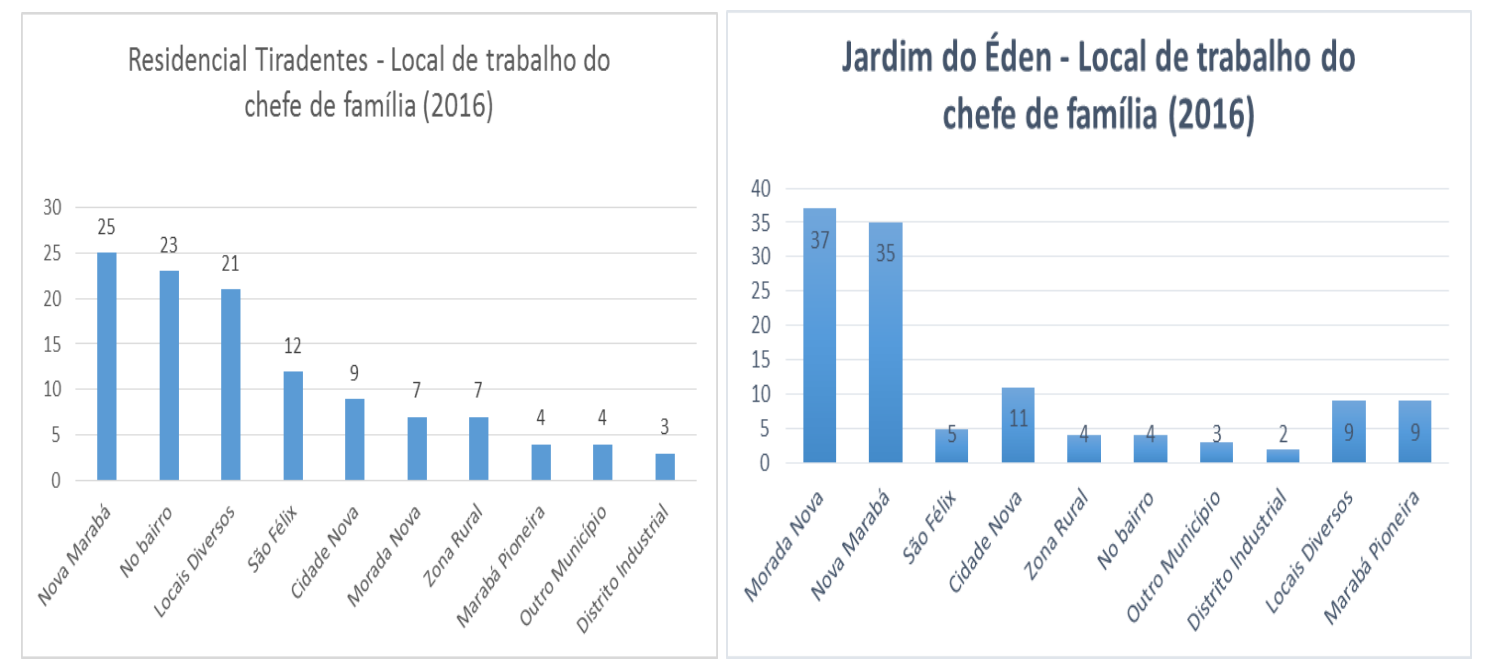

Figura 8 - Residencial Tiradentes e Jardim do Éden: local de trabalho do chefe de família (2015 e 2016) Organização: Souza; Leite (2016). Fonte: Pesquisa de Campo (2015-2016).

Tanto a macroacessibilidade quanto a microacessibilidade se tornam questões importantes ao considerar-se que $44 \%$ dos chefes de família do Residencial Tiradentes dependem do transporte público coletivo para acessar o trabalho e o caso do Jardim do Éden é bastante semelhante, com 45\% dos deslocamentos para o trabalho sendo realizado por este meio de transporte. Em ambos os conjuntos, o transporte público coletivo é o principal meio de acesso dos chefes de família aos seus postos de trabalho.

\section{CONCLUSÃO}

O desenvolvimento da pesquisa possibilitou o contato com aportes teóricos que tratam da questão da produção do espaço urbano, já amplamente debatido na Geografia, 
Dossiê: Impactos e repercussões territoriais de empreendimentos na Pan-Amazônia | Impactos do Programa Minha Casa Minha Vida em Marabá (PA): desigualdades socioespaciais nos conjuntos habitacionais Jardim do Éden e Tiradentes |

| Marcus Vinicius Mariano de Souza | Myrelly Llays Rodrigues Leite |

mas que se tornou um tema novamente relevante no momento atual da realidade brasileira, sobretudo a partir da criação do Programa Minha Casa Minha Vida, proporcionando o retorno do Estado enquanto agente importante na produção do espaço urbano através da provisão de moradias.

É possível fazer uma diferenciação das situações que se apresentam para o Residencial Tiradentes e o Jardim do Éden. Primeiramente, verificou-se que os dois conjuntos habitacionais são locais de moradia de população com uma preocupante situação socioeconômica, com a renda predominante de zero a um salário mínimo, com os chefes de família, em sua maioria, com poucos anos de estudo (predomínio do Ensino Fundamental Incompleto). Nesse aspecto, sobretudo na questão da renda familiar, a situação do Jardim do Éden é pior do que no Tiradentes. Entretanto, um dos vieses de análise da pesquisa foi a inserção urbana e, neste quesito, existem consideráveis diferenças entre os conjuntos.

Apesar de ambos se localizarem distantes da área central da cidade (mais de 20 quilômetros da Marabá Pioneira), o Jardim do Éden, que é o conjunto mais recente de Marabá (entregue em 2015), apresenta uma situação um pouco melhor do que o Tiradentes no que diz respeito à inserção urbana. Para tanto, existe um fator primordial: a localização do Jardim do Éden dentro do Núcleo Morada Nova. Este conjunto pode utilizar-se de todos os equipamentos públicos coletivos, da rede de comércio e serviços que anteriormente já existia em Morada Nova. Isso fica evidente com as formas de deslocamento para utilização de escolas e postos de saúde, que predominantemente é feita a pé pelos moradores do Jardim do Éden.

Em contraposição, o Residencial Tiradentes foi construído em uma área isolada, que anteriormente apresentava usos rurais, estando distante tanto do núcleo São Félix (seis quilômetros) quanto de Morada Nova (três quilômetros), o que tem dificultado sua inserção urbana e, consequentemente, submetido sua população a uma situação de desigualdades socioespaciais. Isto não quer dizer que o Jardim do Éden não esteja, também, submetido a estas condições.

Diante das análises realizadas e dos dados levantados, apresentam-se as seguintes medidas para propor a criação de cenários que possam minimizar a situação de desigualdades socioespaciais a que estão submetidos os moradores destes conjuntos habitacionais:

a) Necessidade de Intervenção no Transporte Público: consideramos que o transporte é o principal problema dos conjuntos, pois a ineficiência deste serviço a acarreta 
Dossiê: Impactos e repercussões territoriais de empreendimentos na Pan-Amazônia | Impactos do Programa Minha Casa Minha Vida em Marabá (PA): desigualdades socioespaciais nos conjuntos habitacionais Jardim do Éden e Tiradentes |

| Marcus Vinicius Mariano de Souza | Myrelly Llays Rodrigues Leite |

em outros problemas. É preciso que haja uma maior disponibilidade de linhas e de horários para atender estes bairros. O transporte público coletivo é o principal meio de acesso dos moradores ao trabalho, aos equipamentos de saúde e ao lazer e, atualmente, as linhas existentes limitam o acesso dos habitantes desses bairros a apenas algumas áreas da cidade;

b) Disponibilidade de novos equipamentos públicos de saúde e educação: esta área da cidade em que se localizam os conjuntos analisados é a única área onde estão sendo instalados os conjuntos habitacionais da Faixa 1 do PMCMV. Isso provoca um aumento da demanda pelos serviços prestados pelos equipamentos de saúde e educação disponíveis. Os três postos de saúde existentes nessa região da cidade são insuficientes para atender à demanda anteriormente existente e à nova demanda criada. Além disso, segundo relatos dos moradores durante a pesquisa, nos postos de saúde são liberadas poucas senhas de atendimento por dia, o que impossibilita o amplo atendimento da população. Uma mudança neste sistema poderia minimizar a precariedade do serviço prestado.

c) Disponibilidade de equipamentos de lazer: chamou atenção durante a pesquisa que, ao serem questionados sobre os locais frequentados para prática de atividades de lazer, a resposta mais frequente dos moradores, em ambos os conjuntos, foi a de que não realizam este tipo de atividade. A explicação para isto pode estar na renda familiar, que é baixa; na dificuldade de acesso a outras áreas da cidade, em virtude da precariedade do transporte público; e das poucas opções de lazer existentes nesta região da cidade (São Félix e Morada Nova).

Por fim, ao serem questionados sobre os aspectos positivos e negativos dos bairros, os moradores deixaram transparecer singularidades importantes de cada um dos conjuntos. No Residencial Tiradentes, a "casa própria" predomina como aspecto positivo do bairro, com 69,4\% das respostas. Já no caso do Jardim do Éden, a casa própria divide a atenção com a "tranquilidade do bairro", já que corresponderam a $42 \%$ e 41,4\% das respostas, respectivamente.

Quanto aos aspectos negativos, no Residencial Tiradentes, a água é a principal reclamação, tanto na questão da distribuição, pois em alguns momentos do dia esta não está disponível, quanto na qualidade, pois às vezes, conforme relatos dos moradores, a água que chega até as casas possui uma coloração amarelada, apresentando-se imprópria para o consumo. A água foi apontada em 36,5\% como o principal aspecto negativo do bairro. Já no caso do Jardim do Éden, apesar de estar localizado ao lado do Núcleo Morada Nova, a distância do conjunto é considerada o principal fator negativo, com 25,7\% das respostas, 
Dossiê: Impactos e repercussões territoriais de empreendimentos na Pan-Amazônia | Impactos do Programa Minha Casa Minha Vida em Marabá (PA): desigualdades socioespaciais nos conjuntos habitacionais Jardim do Éden e Tiradentes |

| Marcus Vinicius Mariano de Souza | Myrelly Llays Rodrigues Leite |

seguida da ineficiência do transporte coletivo, apontada em 20,4\% das respostas. Vale aqui lembrar que o Jardim do Éden está há 25 quilômetros do centro (Marabá Pioneira).

Estes aspectos explicam a insatisfação dos moradores dos conjuntos analisados que, apesar da casa própria, mesmo assim, gostariam de viver em outro local, sobretudo mais próximo da área coesa da cidade, onde estão disponíveis de uma melhor forma (maior acessibilidade) os equipamentos públicos coletivos. Questionados sobre o desejo de viver em outro local, 53\% dos moradores do Jardim do Éden disseram que sim, assim como no Residencial Tiradentes, onde esta resposta alcançou 69\%.

Assim, as análises realizadas através deste trabalho permitiram observar que a lógica de produção do espaço, via Estado, tem como característica atual em Marabá a ampliação de desigualdades socioespaciais, à medida que as formas urbanas surgidas, representadas pelos conjuntos habitacionais, apresentam aspectos problemáticos no que diz respeito à sua inserção urbana. Tal fato dificulta a conexão dos conjuntos habitacionais do PMCMV com o restante da cidade, além de privar, neste sentido, o acesso da população aos bens e serviços públicos de consumo coletivo, tanto pela ausência destes nos conjuntos, quanto pela distância a estes equipamentos em outras áreas da cidade, contribuindo para a ampliação das desigualdades socioespaciais.

\section{AGRADECIMENTOS}

Agradecemos o apoio recebido do Conselho Nacional de Desenvolvimento Científico e Tecnológico - CNPq - Brasil - através do Edital Universal 2016.

\section{REFERÊNCIAS}

ABRAMO, P. O mercado informal e a produção da segregação espacial na América: a cidade COM-FUSA informal. In: LEAL, S.; LACERDA, N. (Org.). Novos padrões de acumulação urbana na produção do habitat: olhares cruzados Brasil-França. Recife: Ed. Universitária UFPE, 2010. p. 211-240.

CARDOSO, Adauto Lúcio; ARAGÃO, Thêmis Amorim. A reestruturação do setor imobiliário e o Programa Minha Casa Minha Vida. In: MENDONÇA, J. P.; COSTA, H. S. M. (Org.). Estado e capital imobiliário: convergências atuais na produção do espaço urbano brasileiro. Belo Horizonte: Ed. C/Arte, 2011. p. 81-104.

CARLOS, Ana Fani Alessandri. A prática espacial urbana como segregação e o "direito à cidade" como horizonte utópico. In: VASCONCELOS, P. A.; CORRÊA, R. L.; PINTAUDI, S. (Org.). A cidade contemporânea: segregação espacial. São Paulo: Contexto, 2013. p. 95-111. 
Dossiê: Impactos e repercussões territoriais de empreendimentos na Pan-Amazônia | Impactos do Programa Minha Casa Minha Vida em Marabá (PA): desigualdades socioespaciais nos conjuntos habitacionais Jardim do Éden e Tiradentes |

| Marcus Vinicius Mariano de Souza | Myrelly Llays Rodrigues Leite |

A condição espacial. São Paulo: Contexto, 2011. 157p.

$270 \mathrm{p}$.

A (re)produção do espaço urbano. 1. ed. 1. reimpr. São Paulo: Edusp, 2008.

FERRAZ, A. C. P.; TORRES, I. G. E. Transporte público urbano. São Carlos: Editora Rima, 2001.

FERREIRA, João Sette Whitaker (Coord.). Produzir casas ou construir cidades? Desafios para um novo Brasil Urbano: parâmetros de qualidade para a implementação de projetos habitacionais e urbanos. São Paulo: LABHAB/FUPAM, 2012. 200p.

FIX, Mariana. Financeirização e transformações recentes no circuito imobiliário no Brasil. 2011. 263 f. Tese (Doutorado em Desenvolvimento Econômico) - Instituto de Economia, Universidade Estadual de Campinas, Campinas, 2011.

GODOY, Paulo Roberto Teixeira. A produção do espaço: uma reaproximação conceitual da perspectiva lefebvriana. Revista GEOUSP, São Paulo, n. 23, p. 125-132, 2008.

LEFEBVRE, Henri. The production of space. Oxford: Blackwell, 1991. 454 p.

MARICATO, Ermínia. O "Minha Casa" é um avanço, mas segregação urbana fica intocada. In: Carta Maior, 25 maio 2009. Disponível em: <http://www.cartamaior.com.br/?/Editoria/Politica/O-Minha-Casa-e-um-avanco-massegregacao-urbana-fica-intocada/4/15160>. Acesso em: 28 out. 2015.

MELAZZO, Everaldo Santos. Estratégias fundiárias e dinâmicas imobiliárias do capital financeirizado no Brasil. Mercator, Fortaleza, v. 12, n. 2 (n. especial), p. 29-40, set. 2013.

RODRIGUES, Arlete Moysés. Desigualdades socioespaciais - a luta pelo direito à cidade. Cidades: Revista Científica, Presidente Prudente, v. 4, n. 6, p. 73-88, 2007.

ROLNIK, Raquel. Guerra dos lugares: a colonização da terra e da moradia na era das finanças. São Paulo: Boitempo, 2015. 423 p.

SHIMBO, Lúcia Z. O "segmento econômico" do mercado imobiliário e os programas públicos: faces da política habitacional contemporânea no Brasil. In: LEAL, S.; LACERDA, N. (Org.). Novos padrões de acumulação urbana na produção do habitat: olhares cruzados Brasil - França. Recife: Ed. UFPE, 2010. p. 123-149.

SOUZA, Marcus Vinicius Mariano. O projeto ALPA e a produção do espaço urbano em Marabá (PA): a cidade-mercadoria e as desigualdades socioespaciais. 2015. 297 f. Tese (Doutorado em Geografia) - Universidade Federal de Uberlândia, Uberlândia, 2015.

VASCONCELOS, Eduardo A. Transporte urbano, espaço e equidade: análise das políticas públicas. 2. ed. São Paulo: Annablume, 2001. 218p. 